\title{
Perceived healthcare workforce needs in Lebanon: a step towards in- formed human resources planning and professional development
}

Mirou Jaana, ${ }^{1}$ Michel Majdalani, ${ }^{2}$ Haitham Tamim ${ }^{3}$ and Rita Rahbany ${ }^{4}$

${ }^{1}$ Telfer School of Management, University of Ottawa, Ottawa, Canada (Correspondence to: Mirou Jaana: jaana@telfer.uottawa.ca). ${ }^{2}$ Adnan Kassar School of Business, Lebanese American University, Beirut, Lebanon. ${ }^{3}$ Digital Health Programme, Algonquin College, Ottawa, Canada. ${ }^{4}$ Syndicate of Hospitals in Lebanon, Beirut, Lebanon.

\begin{abstract}
Background: Research in various countries has previously investigated the competencies required for effective management of health care organizations. Yet, limited information is available on the skills and knowledge areas, which are currently lacking among the healthcare workforce employed in environments with limited resources.

Aims: The aim of this study was to assess the perceived healthcare workforce needs at the management and clinical/ practice levels in Lebanon.

Methods: We conducted an exploratory Delphi study involving two panels of health care professionals and a nationwide survey of hospital directors to assess the skills needed and the healthcare occupations and specialties that are limited.

Results: Based on the Delphi study, the top five needed skills/knowledge areas were: professionalism, ethics, quality management and improvement, strategic planning, and communication. The need for information management and technology skills was reported by more than $50 \%$ of urban hospitals, and highlighted by the two panels in the Delphi study. Healthcare professionals reported willingness to take continuing education courses. Hospitals further indicated the availability of financial support and willingness to collaborate with educational institutions for employee training and continuing education.

Conclusions: Our findings set the ground for future research investigating healthcare workforce issues in Lebanon and support evidence-based planning for health human resources. They may inform the development of national and local policies in the country, which address the human resources needs of the health care system to meet regional and national demands. Universities, professional syndicates, and nongovernmental organizations may leverage these findings to develop continuing education training and diplomas incorporating the competencies critical for the healthcare workforce.
\end{abstract}

Keywords: Delphi; survey; hospitals; human resources; planning

Citation: Jaana M; Majdalani M; Tamim H; Rahbany R. Perceived healthcare workforce needs in Lebanon: a step towards informed human resources planning and professional development. East Mediterr Health J. 2018;24(9):855-865. https://doi.org/10.26719/2018.24.9.855

Received: 22/10/16; accepted: 20/06/17

Copyright (c) World Health Organization (WHO) 2018. Some rights reserved. This work is available under the CC BY-NC-SA 3.o IGO license (https:// creativecommons.org/licenses/by-nc-sa/3.o/igo).

\section{Introduction}

Previous research has investigated the competencies required for effective health care workers and managers (15). Although authors varied in their definition of competency (1), they agreed that it represents the level of skills and knowledge that can be measured against standards and improved by training and development for optimal job performance (6-8).

Competencies are referred to as knowledge, skills and abilities necessary for meeting the changing business and health care needs, and for successful management of health care organizations $(1,3)$. They are context-dependent and should be assessed taking into consideration the critical issues in a health care system and the cultural characteristics of that environment $(1,8)$. It is expected that managers and health professionals combine business practices with clinical and health care knowledge to lead their organizations and contribute to the improvement of their health care system $(3,8,9)$.

Understanding the health care workforce needs is essential for professional development, and for aligning the development at the individual level with the needs of a specific organization or profession (10). In 2005, the World Health Organization (WHO) recommended that future training of the health care workforce incorporate a new set of competencies (e.g., quality improvement, information and communication technology, etc.) to support health workers in managing the most prevalent problems of the 21st century (2). More recently, WHO called health professionals' education and training institutions to implement continuous development programmes and use adapted training curricula that address timely challenges and the evolving needs of their communities (11). Yet, knowledge about the specific needs of the health care workforce in various health care systems in resource-constrained environments, including Lebanon, remains limited.

The health care system in Lebanon has been facing challenges and uncertainties (12), which have put significant pressure on health care professionals and organizations. Lebanon has 28 public and 134 private 
hospitals (13), various nongovernmental organizations and dispensaries targeting primary health care in underprivileged regions (14), and other entities catering mostly towards the provision of curative care (15). As of 2013, the distribution of health professionals per 10000 citizens was 31.9 physicians, 33.1 nurses and midwives, and 16.8 dentists (16). Although the health care sector is partly funded by 7 public schemes $(13,17)$, services are mostly paid for out-of-pocket or through private health insurance. The system is largely dominated by the private sector $(13,18)$, which remains highly unregulated (19).

A major concern in Lebanon is the absence of a national health policy on human resources and the lack of a long-term strategy regulating the recruitment and distribution of health care professionals. A significant brain drain has been observed historically, especially for the nursing profession, with the migration of nurses for better conditions and pay (20). The main challenges facing the health care workforce in Lebanon include imbalanced professional and geographic distribution of providers/ institutions, lack of relicensing of health professionals or accreditation of curricula, and limited continuing education programmes and career development (21).

A quick search of the literature and online resources shows very limited resources available for continuing education in Lebanon. With the exception of information available online on continuing education centres and divisions in various universities in the country, only two studies discussed continuing education and professional development in relation to the health care workforce. One study showed that nurses in Lebanon attend insufficient continuing education sessions per year (22). More recently, Alameddine et al. investigated factors associated with staff retention at primary health care centres in Lebanon, and reported that among the top three reasons behind the likelihood to quit is the lack of professional development, reported by around one-third of surveyed providers (23).

This article contributes to this under-researched area and explores the perceived health care workforce needs (at the management and clinical/practice levels), which may inform future efforts for professional development and human resources planning. Specifically, a 2-stage project, including a Delphi exploratory survey of health care professionals and a nationwide survey of hospitals, was conducted to identify the skills needed by the health care workforce in Lebanon today and the health care occupations and medical specialties that are in short supply in the country.

\section{Methods}

\section{Exploratory stage: a qualitative Delphi evaluation}

We conducted an exploratory Delphi survey to uncover the health care professionals' perspectives of the workforce skills needs in Lebanon (Table 1). Since no prior research has been done in this area, it was necessary to start with an exploratory assessment. The Delphi method is a valuable data-driven approach that is often used in exploratory studies when evidence on a topic or question is scarce (24). It usually consists of a 3-phase data collection approach (brainstorming, narrowing down, and ranking), which employs a set of linked questionnaires eliciting the opinion of panels of experts in a certain field through iterative feedback (25).

In order to ensure the representativeness of different groups of practitioners, two panels of experts were invited to participate in the Delphi part of the project; one panel included allied health care professionals (i.e., non-medical health professionals) and the second panel consisted of physicians. A convenient sample of panellists within each group was recruited with the intention to have as much representation as possible of various stakeholders within each group (e.g. area of specialization, employment).

At the beginning of the project, we intended to recruit 18 participants in each group in order to account for potential attrition over the three rounds. Hence, we attempted to reach out to 18 physicians and 18 allied professionals in the community. However, we were not

\section{Table 1 Delphi study phases}

\section{Phase 1. Brainstorming}

Five most important skills/knowledge areas in the field of health care administration/management were solicited from practicing health care professionals

Two panels of respondents recruited: physicians \& allied health care professionals

11 physicians and 11 allied professionals completed Phase 1

A total of 80 skills/knowledge areas were identified by the 2 panels

Final combined list consisted of 21 unique skills/knowledge areas after removing duplicates and merging similar issues

\section{Phase 2. Narrowing down}

The two panels (nine physicians and 10 allied professionals) pared the list down

Panellists selected 1o skills/knowledge areas that they perceived as most needed

Issues identified by at least half of each panel were retained

Total of 16 skills/knowledge areas were retained by both panels

\section{Phase 3. Ranking}

The two panels separately produced a ranked list of needed skills/knowledge areas ( 9 physicians and 9 allied professionals)

Degree of consensus was calculated using Kendall's coefficient of concordance (W)

Fair level of consensus was reached within each panel ( $W=0.37$ for the physicians panel; $W=0.33$ for the allied professionals panel) 
able to reach some of them despite multiple attempts. Subsequently, we successfully communicated with 15 allied professionals and 14 physicians who were invited to participate in the Delphi project; details about the three rounds were shared with them. 14 allied professionals and 13 physicians agreed to participate. Among these, 11 participants in each panel answered the first round, representing an $81 \%$ response rate.

Data collection from the two panels was conducted over a period of five months by e-mail, which is an approach that has been used in Delphi surveys as it allows flexibility and supports timely responses. In Phase 1 , brainstorming, the panellists received the first questionnaire asking them to identify five most critical skills and/or knowledge areas that are needed, and expected to be in need, over the next three years. They were also asked to provide a brief definition of the skills that they presented. Responses were reconciled after removing duplicates and grouping similar answers.

In Phase 2, narrowing down, the consolidated list of skills/knowledge areas generated in Phase 1 was randomly ordered and sent back to the panellists for validation. The respondents were asked to select from this list the 10 skills/knowledge areas that they consider most needed. General questions related to the profile of the participants were also included.

In Phase 3, the experts received the random list of skills/knowledge areas that were retained by at least 50\% of the two panels in Phase 2, and were asked to order them from the most to the least needed. Kendall coefficient of concordance $(\mathrm{W})$ was calculated to determine the level of consensus between participants in each panel.

\section{Hospital administrators' survey}

The survey component aimed to provide an overview of the perspectives of hospital administrators/chief executive officers regarding the current health care workforce needs in Lebanon. Given the relatively small number of public hospitals in Lebanon and the limited information available on them, the survey targeted private hospitals, which are considered the "backbone" of the healthcare system in Lebanon (13). The Syndicate of Private Hospitals in Lebanon, which represent more than $75 \%$ of hospitals endorsed the survey; the questionnaire was reviewed by its board, and the centralized list of hospitals available at the syndicate was used for data collection.

The results of the exploratory stage of the project were used for the development of the questionnaire, combined with evidence from similar studies in the literature in other contexts. The questionnaire included closed-ended questions that assessed the need for 15 management skills and 9 clinical/practice skills among the health care workforce in hospitals. It also investigated the extent to which 12 health care professions and 10 medical specialties are currently needed in hospitals, and examined the training resources that would best meet the skill needs of the health care workforce.

The questionnaire was distributed to 134 hospitals in Lebanon; copies were both e-mailed and faxed as per common practice/procedure for surveys involving hospitals with the Syndicate. Data collection took place over a period of three months, July-September 2014, and a reminder was sent half-way through. A total of 33 hospitals completed the survey, a 25\% response rate. Descriptive data through analyses were performed to provide an overview of the health care workforce skills and occupations needed by hospitals in Lebanon, the available training resources and options, and the financial support for continuing education.

\section{Results}

\section{Exploratory Delphi evaluation}

The participants in the Delphi component of the project were mostly women aged 30-50 years, who had considerable years of experience (Table 2). The majority of allied professionals held a Master's degree in various areas of specialization, including nursing, osteopathy, pharmacy and management. The panel of physicians was also diverse and included various specialties. More than $50 \%$ of the panellists were employed in private hospitals and all participants reported having taken continuing education courses and would consider doing so in the future.

In total, 80 skills/knowledge areas were identified by the two panels in Phase 1.Theresponses were consolidated, producing a final list of 21 unique skills/knowledge areas (Table 3). Eleven of these were overlapping between the two panels (Table 4).

The consolidated list was randomly ordered and sent back to the two panels for narrowing down (Phase 2). Overall, 16 skills were retained as they were selected by at least $50 \%$ of either of panel. Eleven out of the 16 were identified by more than $50 \%$ of participants in both panels (Table 4), of which 7 were also identified by both panels in Phase 1: information and communication technology; ethics in health care delivery; quality management and improvement in health care; financial health care management; inter-professional collaboration and teamwork; communication skills; and professionalism.

In Phase 3, the panellists were asked to rank the random list of 16 skills/knowledge areas retained from phase 2. The level of agreement was "fair" for both panels: $\mathrm{W}=0.37$ for the physicians; $\mathrm{W}=0.33$ for the allied professionals. The ranking further confirmed the similarities between the panels with respect to the most needed skills relevant to the health care practice environment today (Table 5): ethics in health care delivery (ranked no. 1 by both panels), professionalism, quality management and improvement in health care, evidencebased health care management and strategic planning and management.

\section{Hospital administrators' survey: perceived needs}

Surveyed hospitals were mostly urban $(70 \%)$ and general, nonspecialized hospitals (75\%). The average number of staffed beds was 174 (range 24-100o). The top three 


\begin{tabular}{|c|c|c|c|c|c|c|}
\hline \multirow[t]{2}{*}{ Characteristic } & \multicolumn{2}{|c|}{ Physicians } & \multicolumn{2}{|c|}{ Allied professionals ${ }^{a}$} & \multicolumn{2}{|c|}{ Overall sample } \\
\hline & No. & $\%$ & No. & $\%$ & No. & $\%$ \\
\hline \multicolumn{7}{|l|}{ Sex } \\
\hline Male & 3 & 33 & - & - & 3 & 16 \\
\hline Female & 6 & 67 & 10 & 100 & 16 & 84 \\
\hline \multicolumn{7}{|l|}{ Age (years) } \\
\hline $30-39$ & 2 & 22 & 2 & 20 & 4 & 21 \\
\hline $40-49$ & 6 & 67 & 7 & 70 & 13 & 68 \\
\hline $50-59$ & 1 & 11 & - & - & 1 & 5 \\
\hline$\geq 60$ & - & - & 1 & 10 & 1 & 5 \\
\hline \multicolumn{7}{|l|}{ Highest education } \\
\hline Undergraduate & - & - & 2 & 20 & 2 & 11 \\
\hline Masters & - & - & 7 & 70 & 7 & 37 \\
\hline Doctorate (PhD) & - & - & 1 & 10 & 1 & 5 \\
\hline Medicine (MD) & 9 & 100 & - & - & 9 & 47 \\
\hline \multicolumn{7}{|l|}{ Area of specialization } \\
\hline Pharmacy & - & - & 1 & 10 & 1 & 5 \\
\hline Management & - & - & 4 & 40 & 4 & 21 \\
\hline Nursing & - & - & 3 & 30 & 3 & 16 \\
\hline Osteopathy & - & - & 110 & - & 1 & 5 \\
\hline General/family medicine & 3 & 33 & - & - & 3 & 16 \\
\hline Paediatrics & 2 & 22 & - & - & 2 & 11 \\
\hline Surgery & 2 & 22 & - & - & 2 & 11 \\
\hline Dermatology & 1 & 11 & - & - & 1 & 5 \\
\hline Missing & 1 & 11 & 1 & 10 & 2 & 11 \\
\hline \multicolumn{7}{|c|}{ Previously taking continuing education courses } \\
\hline Yes & 9 & - & 10 & 100 & 19 & 100 \\
\hline \multicolumn{7}{|c|}{ Consider taking continuing education courses } \\
\hline Yes & 9 & - & 10 & 100 & 19 & 100 \\
\hline \multicolumn{7}{|l|}{ Main location/type of employment } \\
\hline Private hospital & 5 & 56 & 6 & 60 & 11 & 58 \\
\hline Private clinic & 2 & 22 & 1 & 10 & 3 & 16 \\
\hline Nongovernmental organization & 2 & 22 & 2 & 20 & 4 & 21 \\
\hline University & - & - & 1 & 10 & 1 & 5 \\
\hline \multicolumn{7}{|l|}{ Years of experience } \\
\hline Mean (standard deviation) & \multicolumn{2}{|c|}{$13.4(5.4)$} & \multicolumn{2}{|c|}{$19.3(10.4)$} & \multicolumn{2}{|c|}{$16.7(9.0)$} \\
\hline Min-max & \multicolumn{2}{|c|}{$5-20$} & \multicolumn{2}{|c|}{$1-38$} & \multicolumn{2}{|c|}{$1-38$} \\
\hline
\end{tabular}

ane of the 10 allied professionals who completed phase 2 (including questions about profile of the respondents) did not answer Phase 3.

management skills reported as needed by more than half of the sample were: communication and interpersonal skills (72.7\%), critical thinking and problem solving (57.6\%), and strategic planning (54.5\%) (Table 6). Almost half of the sample ( $48.5 \%$ of the responding hospitals) reported needs in health information technology/systems. The need for certain skills varied based on the urban/rural status. For example, more than $50 \%$ of urban hospitals reported the need for skills in quality management and improvement (52.2\%), whereas rural hospitals identified a need for human resources management skills (50.0\%).
Three clinical/practice skills were identified as needed by more than half the surveyed hospitals: professional behaviour (72.7\%), patient education (69.7\%) and evidencebased care (51.5\%). Urban hospitals also noted a need for clinical information management and sharing (52.2\%), while rural hospitals identified a need in geriatric care (60\%).

The health care occupations and medical specialties reported as needed on a $1-5$ scale $(1=$ not needed at all; 5 = strongly needed) were: registered nurses (mean 4.4), nurse practitioners (mean 3.2), information technology 
Table 3 Description of skills/knowledge areas identified in the consolidated list from Phase 1 of the Delphi evaluation

\section{Skills/knowledge area}

Information and communication technology

Ethics in health care delivery

Paramedic training

Geriatric and chronic care

Quality management and improvement in health care

Health systems and policies

Strategic planning and management

Financial health care management

Trauma and critical care

Methodology and approaches for workshop development

Communication skills

Leadership

Professionalism

Home-based health care delivery

Efficiency and streamlining of health care processes

Evidence-based health care management

Conflict resolution

Patient safety

Critical analysis and problem solving

Human resources strategies and management

\section{Description based on participants' responses}

Skills related to innovation and technology including information search, the Internet, communication technology and implementation of unified charting systems and electronic medical records

Knowledge and application of moral conduct in the delivery of patient care taking into consideration the legal, cultural and humane dimensions

Basic life support training and first aid administration skills for paramedics and overall health care professional population

Understanding, education and training in geriatric and chronic patient care

Knowledge about quality management and control and the application of patient cantered, standardized and evidence based care

Knowledge of the health care environment and global health systems as well as health policy formulation, implementation and interaction with policy-makers

Skills related to the strategic planning process, implementation of strategic plans, and organizational development

Knowledge of health care management areas, including dealing with third party payers, insurance arrangements, reimbursement to payers, budget planning and cost effectiveness

Inter-professional education development, shared decision-making and responsibilities, and communication between teams and clinical departments (anaesthesia, radiology etc.)

Knowledge of updated clinical steps and procedures for trauma and critical care.

Ability to organize and develop workshops addressing emergent health care issues in society and encourage lifelong learning

Communication skills applied to clinical and non-clinical areas, including: oral skills, e.g. inter-professional communication or communication with patients, and writing skills, e.g. memos, articles, charting, clinical reports, and care plans

Leadership skills and practices, showing class, character, and the ability to manage change in health care sector

Maintaining professional conduct and avoiding preferential treatment related to health care professionals, as well as patient care.

Knowledge of the components and resources needed for home-based care and the arrangements necessary to support its delivery

Developing efficient practices in delivering care and streamlining health care processes

Applying existing evidence to support and improve decision-making in health care organizations

Knowledge of group dynamics and conflict resolution abilities

Empowerment and engagement of employees to promote a culture of safety and support reporting adverse events

Knowledge of the research process, and the steps in conducting a research project, including data collection and analysis to support decision-making

Knowledge of motivation principles and practices, as well as strategies for staff retention and satisfaction, e.g. understanding health care workers jobs and responsibilities, providing relief sessions against burnout and organizational behaviour skills specialists (mean 3.1), physician assistants (mean 2.6), laboratory technicians (mean 2.5) and general practitioners (mean 2.5) (Table 7). The top four health care professions that are most needed were common to urban and rural hospitals; only laboratory technicians and general practitioners were more needed in urban and rural hospitals, respectively, compared to their counterparts.

The medical specialties reported as needed by the surveyed hospitals were: emergency medicine (mean 3.7) and radiology (mean 3.1) (Table 7). Urban hospitals reported a greater need for anaesthesiologists (mean 2.9 vs 2.3 in the rural group) whereas rural hospitals had a shortage in numerous specialties such as surgery (mean 3.7), obstetrics/gynaecology (mean 2.9), paediatrics (mean 2.8) and internal medicine (mean 2.6).

The great majority of responding hospitals identified continuing education courses (91\%), collaboration with educational institutions for training (88\%), seminars (82\%) and in-house/on-the-job training (73\%) as opportunities to meet the skills needs of their workforce. A smaller number indicated that they would consider on-line 


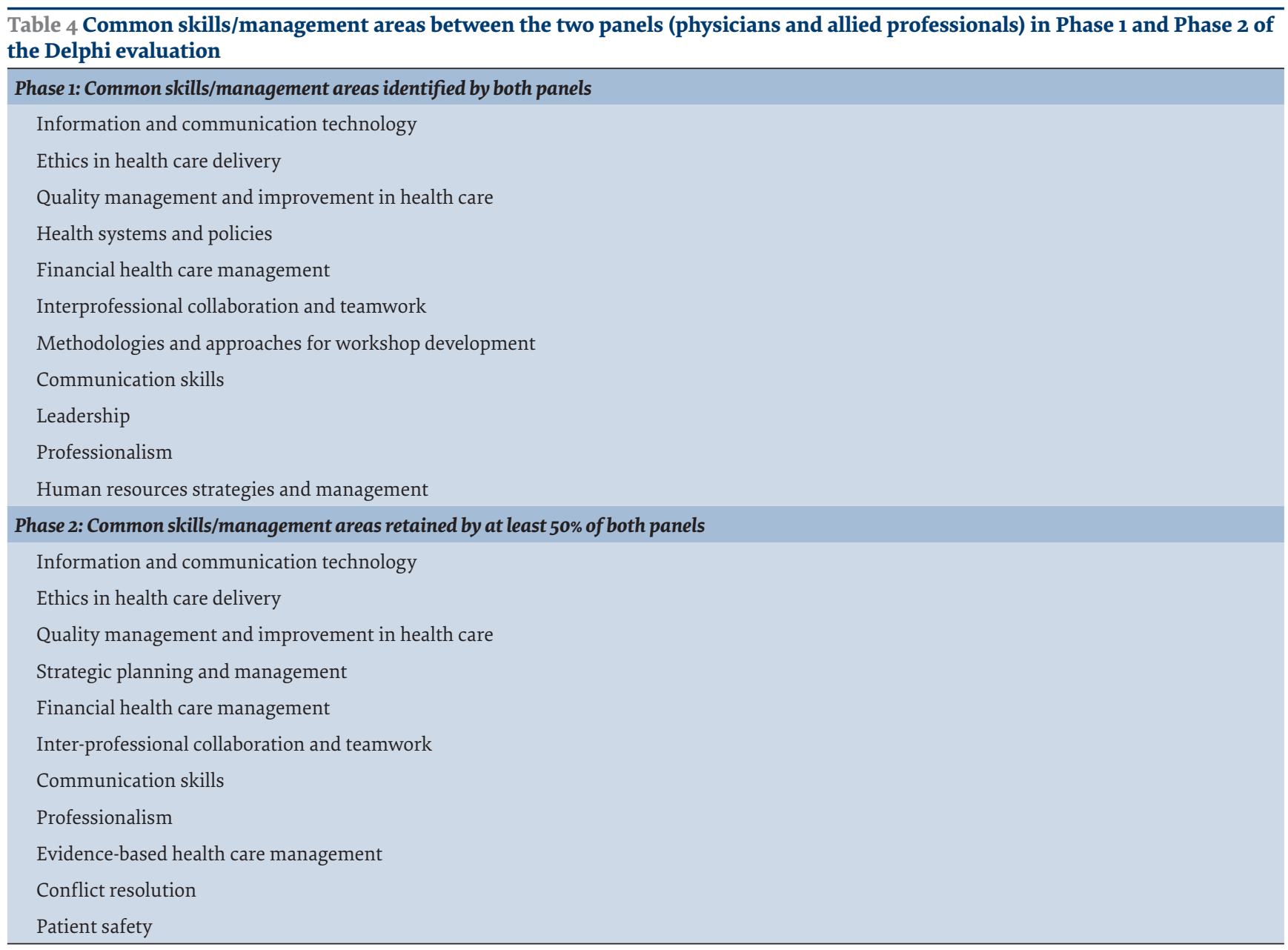

Table 5 Final ranking of the needed skills/knowledge areas identified by the two panels of health care professionals (physicians and allied professionals) in phase 3 of the Delphi evaluation

\begin{tabular}{lllll}
\multicolumn{3}{c}{ Ranking } & \multicolumn{1}{c}{ Needed skills/knowledge areas } \\
$\mathbf{0}$ & $\mathbf{P}$ & AP & \\
1 & 1 & 1 & Ethics in health care delivery \\
2 & 2 & 3 & Professionalism \\
3 & 4 & 2 & Quality management and improvement in health care \\
4 & 3 & 7 & Evidence-based health care management \\
5 & 6 & 4 & Strategic planning and management \\
6 & 8 & 6 & Leadership \\
7 & 4 & 8 & Inter-professional collaboration and teamwork \\
8 & 5 & 9 & Communication skills \\
9 & 10 & 5 & Information and communication technology \\
10 & 7 & 11 & Paramedic training \\
11 & 6 & 13 & Patient safety \\
12 & 11 & 14 & Efficiency and streamlining of health care processes \\
13 & 13 & 12 & Conflict resolution \\
14 & 14 & 10 & Financial health care management \\
15 & 12 & 15 & Critical analysis and problem solving \\
16 & 9 & 16 & Home-based health care delivery \\
\hline
\end{tabular}

$O=$ overall rank.

$P=$ physicians panel.

$A P=$ allied professionals panel. 


\begin{tabular}{|c|c|c|c|c|c|}
\hline \multirow[t]{2}{*}{ Skill } & \multicolumn{2}{|c|}{$\begin{array}{c}\text { Urban } \\
(n=23)\end{array}$} & \multicolumn{2}{|c|}{$\begin{array}{c}\text { Rural } \\
(n=10)\end{array}$} & \multirow{2}{*}{$\begin{array}{c}\text { Total } \\
(n=33)\end{array}$} \\
\hline & $\%$ of total & $\%$ of urban & $\%$ of total & $\%$ of rural & \\
\hline \multicolumn{6}{|l|}{ Management } \\
\hline Communication and interpersonal skills & 48.5 & 69.6 & 24.2 & 80.0 & 72.7 \\
\hline Critical thinking and problem solving & 39.4 & 56.5 & 18.2 & 60.0 & 57.6 \\
\hline Strategic planning & 42.4 & 60.9 & 12.1 & 40.0 & 54.5 \\
\hline Health information technology/systems & 36.4 & 52.2 & 12.1 & 40.0 & 48.5 \\
\hline Quality management and improvement & 36.4 & 52.2 & 9.1 & 30.0 & 45.5 \\
\hline Human resources management & 30.3 & 43.5 & 15.2 & 50.0 & 45.5 \\
\hline Patient safety & 33.3 & 47.8 & 9.1 & 30.0 & 42.4 \\
\hline Financial management & 30.3 & 43.5 & 12.1 & 40.0 & 42.4 \\
\hline Leadership & 30.3 & 43.5 & 12.1 & 40.0 & 42.4 \\
\hline Report writing & 33.3 & 47.8 & 9.1 & 30.0 & 42.4 \\
\hline Ethics & 30.3 & 43.5 & 9.1 & 30.0 & 39.4 \\
\hline Research design and implementation & 24.2 & 34.8 & 12.1 & 40.0 & 36.4 \\
\hline Health programmes/interventions evaluation & 24.2 & 34.8 & 9.1 & 30.0 & 33.3 \\
\hline Health programmes/interventions planning & 12.1 & 17.4 & 12.1 & 40.0 & 24.2 \\
\hline Presentation skills & 12.1 & 17.4 & 3.0 & 10.0 & 15.2 \\
\hline \multicolumn{6}{|l|}{ Clinical/practice } \\
\hline Professional behaviour (communicating with patients) & 48.5 & 69.6 & 24.2 & 80.0 & 72.7 \\
\hline Patient education & 42.4 & 60.9 & 27.3 & 90.0 & 69.7 \\
\hline Evidence-based care (using research evidence) & 39.4 & 56.5 & 12.1 & 40.0 & 51.5 \\
\hline Clinical information management and sharing & 36.4 & 52.2 & 9.1 & 30.0 & 45.5 \\
\hline Adoption of clinical guidelines & 30.3 & 43.5 & 12.1 & 40.0 & 42.4 \\
\hline $\begin{array}{l}\text { Nursing documentation (e.g., patient condition assessment, vitals, } \\
\text { nursing interventions) }\end{array}$ & 24.2 & 34.8 & 15.2 & 50.0 & 39.4 \\
\hline Geriatric (elderly) care & 18.2 & 26.1 & 18.2 & 60.0 & 36.4 \\
\hline Critical care and trauma & 18.2 & 26.1 & 9.1 & 30.0 & 27.3 \\
\hline Technical skills (e.g. procedures, tests) & 21.2 & 30.4 & 6.1 & 20.0 & 27.3 \\
\hline
\end{tabular}

courses $(24 \%)$ or private consultants $(40 \%)$. A majority of hospitals offered financial support for continuing education (96\%), and had an annual budget (83\%) for it.

\section{Discussion}

This project combined qualitative and quantitative methods to address an under-researched area and identify the perceived health care workforce needs in Lebanon. It is particularly relevant today in light of the growing pressure on the health care system in Lebanon with an increasing number of refugees, chronic internal challenges (e.g. brain drain, population aging and chronic diseases, limited resources) and the potential active role of the country in medical tourism.

This project faced some limitations that are important to highlight. We encountered challenges in recruiting men for the Delphi panels, which is reflective of the current workforce demographics in the country. This confirms evidence from recent reports that discussed out-migration of young men in search of work $(19,21)$ and the cultural reputation surrounding some professions as being labelled for women. The survey response rate was $25 \%$, though there was a good representation of both rural and urban hospitals in the sample. We were not able to pilot test the instrument, however it was reviewed by the Board of the Syndicate of Hospitals. The available list of hospitals from the syndicate turned out not be fully updated: some hospitals on the list were not functional, or not reachable at the time of the project due to outdated information. Hence, we believe that the response rate was more on the conservative side. The fact that the surveyed hospitals were all private, although the majority of hospitals in Lebanon are private, may affect the generalizability of the results to public hospitals. It is important to note that, given the nature of the project, self-reporting bias may have occurred. Since this project is the first to investigate the health care workforce needs, it is not possible to compare or benchmark the results against other similar studies in this area.

The findings of the two parts of this project reveal consistency in the top 5 skills/knowledge areas 


\begin{tabular}{|c|c|c|c|c|c|c|c|c|c|}
\hline \multirow[t]{2}{*}{ Profession/specialty } & \multicolumn{3}{|c|}{ Urban hospitals } & \multicolumn{3}{|c|}{ Rural hospitals } & \multicolumn{3}{|c|}{ Total } \\
\hline & No. & $\begin{array}{l}\text { Mean } \\
\text { (SD) }\end{array}$ & Range & No. & $\begin{array}{c}\text { Mean } \\
\text { (SD) }\end{array}$ & Range & No. & $\begin{array}{l}\text { Mean } \\
\text { (SD) }\end{array}$ & Range \\
\hline \multicolumn{10}{|l|}{ Health care professions } \\
\hline Registered nurse & 22 & $4.3(1.1)$ & $2-5$ & 10 & $4.6(0.8)$ & $3-5$ & 32 & $4.4(1.0)$ & $2-5$ \\
\hline Nurse practitioner & 22 & $3.1(1.6)$ & $0-5$ & 10 & $3.6(1.7)$ & $0-5$ & 32 & $3.2(1.6)$ & $0-5$ \\
\hline Information technology specialist & 21 & $3.1(1.6)$ & $0-5$ & 10 & $2.9(1.5)$ & $0-5$ & 31 & $3.1(1.6)$ & $0-5$ \\
\hline Physician assistant & 21 & $2.5(1.9)$ & $0-5$ & 8 & $2.8(1.4)$ & $0-5$ & 29 & $2.6(1.8)$ & $0-5$ \\
\hline Laboratory technician & 22 & $2.6(1.6)$ & $0-5$ & 9 & $2.2(1.4)$ & $0-4$ & 31 & $2.5(1.5)$ & $0-5$ \\
\hline General practitioner & 22 & $2.4(1.7)$ & $0-5$ & 9 & $2.9(1.6)$ & $0-5$ & 31 & $2.5(1.6)$ & $0-5$ \\
\hline Social care worker & 21 & $2.0(1.9)$ & $0-5$ & 8 & $2.1(2.0)$ & $0-5$ & 29 & $2.0(1.9)$ & $0-5$ \\
\hline Radiation therapist/technician & 21 & $2.1(1.5)$ & $0-5$ & 9 & $1.7(1.6)$ & $0-4$ & 30 & $2.0(1.5)$ & $0-5$ \\
\hline Dietician & 22 & $2.0(1.5)$ & $0-5$ & 9 & $1.9(1.2)$ & $0-4$ & 31 & $2.0(1.4)$ & $0-5$ \\
\hline Clinical psychologist & 22 & $1.7(1.8)$ & $0-5$ & 9 & $1.1(1.4)$ & $0-4$ & 31 & $1.6(1.7)$ & $0-5$ \\
\hline Physiotherapist & 21 & $1.6(1.3)$ & $0-5$ & 9 & $1.4(1.3)$ & $0-4$ & 30 & $1.5(1.3)$ & $0-5$ \\
\hline Speech therapist & 21 & $1.5(1.6)$ & $0-5$ & 8 & $0.9(1.5)$ & $0-4$ & 29 & $1.3(1.6)$ & $0-5$ \\
\hline \multicolumn{10}{|l|}{ Medical specialties } \\
\hline Emergency medicine & 21 & $3.5(1.8)$ & $0-5$ & 10 & $4.2(1.2)$ & $2-5$ & 31 & $3.7(1.7)$ & $0-5$ \\
\hline Radiology & 21 & $2.8(1.8)$ & $0-5$ & 9 & $3.8(1.5)$ & $1-5$ & 30 & $3.1(1.7)$ & $0-5$ \\
\hline Surgery & 21 & $2.6(1.9)$ & $0-5$ & 9 & $3.7(1.2)$ & $2-5$ & 30 & $2.9(1.7)$ & $0-5$ \\
\hline Anaesthesiology & 21 & $2.9(1.1)$ & $1-5$ & 9 & $2.3(1.8)$ & $0-5$ & 30 & $2.7(1.7)$ & $0-5$ \\
\hline Internal medicine & 21 & $2.5(1.7)$ & $0-5$ & 8 & $2.6(1.4)$ & $1-5$ & 29 & $2.5(1.6)$ & $0-5$ \\
\hline Obstetrics/gynaecology & 21 & $2.3(1.9)$ & $0-5$ & 9 & $2.9(1.5)$ & $1-5$ & 30 & $2.5(1.7)$ & $0-5$ \\
\hline Paediatrics & 21 & $2.4(1.7)$ & $0-5$ & 9 & $2.8(1.4)$ & $1-5$ & 30 & $2.5(1.6)$ & $0-5$ \\
\hline Pathology & 20 & $2.4(2.0$ & $0-5$ & 9 & $2.3(1.2)$ & $1-5$ & 29 & $2.35(1.7)$ & $0-5$ \\
\hline Palliative care & 21 & $2.4(1.8)$ & $0-5$ & 8 & $2.1(2.0)$ & $0-5$ & 29 & $2.3(1.8)$ & $0-5$ \\
\hline
\end{tabular}

$S D=$ standard deviation.

identified as needed: professionalism, evidence-based management, strategic planning, quality management and improvement, and communication skills. Interestingly, ethics ranked first in terms of need in the Delphi results; yet, it was reported as needed by only $40 \%$ of hospitals. Leadership ranked sixth by the two panels and was reported as needed by only $42 \%$ of hospitals. This may be explained by the nature of the work of health professionals (i.e. direct contact with patients and providers), which allows them to better capture the ethics and leadership dimensions.

The findings of this project show consistency with other studies $(3,9,26)$ and with the recommendations of WHO in relation to quality improvement, partnering, and information and communication technology. These competencies have been identified by WHO as basic for continuing professional development and effective delivery of care for patients, especially in developing countries $(2,11)$. It called for a shift in training to incorporate these competencies and for sustained educational reform $(2,11,27)$. Ten years later, these skills are still not addressed in Lebanon: quality improvement, communication, and information management and technology were identified as being in need. This indicates that the health care workforce is still not ready and equipped to cope with the changes and pressures observed at the population and health system levels.

Although clinical skills (e.g. trauma and critical care, geriatric and chronic care) appeared in the responses of the two panels, these were not retained in the final stages of the Delphi study results. Clinical skills were also referred to by hospital administrators (e.g. geriatric care, adoption of clinical guidelines etc.), but were not considered among the most needed. This emphasizes the fact that areas beyond clinical expertise are pressing today, and should be addressed. Traditional health care professionals' curricula tend to emphasize mostly the clinical aspects of training, with educational programmes for health providers being focused on preparing the workforce for the hospital environment (23). A recent article on health system research priorities in the Middle East and North Africa region emphasized the need for research on the health workforce (21). It identified gaps in existing education and training programmes, accurate estimates and needs (numbers and specialties) and ways for enabling education and training programmes based on population needs as being among the top five research areas in health human resources. Hence, this project 
contributes to this research agenda and highlights priorities that set the stage for future research in this area and professional development of health professionals.

In addition to the contribution of this project to the relevant research priorities in human health resources identified earlier (21), it also has implications at the practice and policy level by supporting effective health care workforce planning at the organizational and national level. The results may inform the development of national and local policies in the context of Lebanon, which establish guidelines for a desired level of skills mix in the health care workforce in rural and urban settings. They also outline areas of continuing education and professional development and present evidence that can be used by hospitals to compare and benchmark their needs to other similar organizations. The results may also be used as a starting point to open the dialogue between academic institutions and health care organizations, and unveil potential opportunities of collaboration and partnership between them to address the training needs of the healthcare workforce.

The two panels of physicians and allied professionals reported a willingness to take continuing education courses, and most hospitals indicated available financial support for this (100\% of rural hospitals and $80 \%$ of urban hospitals). This is an interesting finding considering the culture in Lebanon that may not be conducive to supporting continuing education efforts (e.g., limited resources and incentives, lack of structured organized efforts for continuing education - credits and certificates, limited evidence on association between continuing education and progression through rank and position etc.). Hence, the results of this study should motivate dialogue and collaboration between hospitals, professional syndicates and universities for the development of continuing education courses and programmes addressing the identified needs. This is in line with recent calls by the WHO (2013) for more alignment between educational institutions and the systems delivering health services (11).

Competency-based education has been advocated as essential for educational reform and for aligning educational programmes with actual health systems priorities, especially in environments with limited resources (8). It allows the integration of the health needs of the population with the priority areas of the health profession. Competence in certain domains can be very dependent on the context of the country and the resources available. Therefore, instead of adapting existing foreign educational standards from resource-rich settings, which may not be compatible with the actual needs of Lebanon, one can build on the findings of this project to develop relevant programmes that target the skill needs of health workers in the country. In conclusion, the findings from this project present a first step towards informing human resources planning and professional development, and set the stage for future studies to build further evidence in this area.

\section{Acknowledgements}

The authors thank Ms Hiba Shahine, MBA, and Ms Lamis Samad, MBA, for their valuable assistance in the project. The authors would also like to thank the Syndicate of Hospitals in Lebanon for their endorsement of the survey in the project. A preliminary version of the project and results was presented to the Lebanese American University and the Syndicate of Hospitals in Lebanon.

Funding: This research was supported through funding from the Division of Continuing Education Programme at the Lebanese American University.

Competing interests: None declared.

\section{La perception des besoins par les personnels de soins de santé au Liban : un pas en avant vers une planification éclairée des ressources humaines et du développement professionnel}

\section{Résumé}

Contexte : Des recherches ont déjà été menées dans plusieurs pays au regard des compétences requises pour gérer de façon efficace les organismes de soins de santé. Pourtant, peu de données sont disponibles concernant les compétences et les domaines de connaissances qui font actuellement défaut parmi les personnels de soins de santé travaillant dans des environnements disposant de ressources limitées.

Objectif : L'objectif de la présente étude était d'évaluer la perception des besoins par les personnels de soins de santé au Liban.

Méthodes : Nous avons mené une étude exploratoire suivant la méthode de Delphi, faisant intervenir deux groupes de professionnels de soins de santé et comportant une enquête nationale menée auprès de directeurs d'établissements hospitaliers afin d'évaluer les compétences nécessaires et les métiers et spécialités faisant défaut dans le secteur des soins de santé. 
Résultats : Sur la base de l'étude Delphi, les cinq principaux domaines où se fait sentir le besoin en compétences et en connaissances sont les suivants : le professionnalisme, l'éthique, la gestion et l'amélioration de la qualité, la planification stratégique, la gestion et l'amélioration de la qualité et la communication. Le besoin en matière de gestion de l'information et de compétences technologiques a été mentionné par plus de 50 \% des hôpitaux urbains et a été mis en avant par les deux groupes de professionnels de l'étude Delphi. Les professionnels de soins de santé se sont déclarés prêts à suivre des cours de formation continue. Les hôpitaux ont par aileurs indiqué la disponibilité de moyens financiers et leur volonté de collaborer avec les établissements d'enseignement afin de faire bénéficier leur personnel de formations et de sessions de formation continue.

Conclusion : Nos résultats préparent le terrain pour des recherches futures portant sur les problèmes des personnels de soins de santé au Liban et viennent étayer une planification des ressources humaines fondée sur des données probantes. Ils pourraient éclairer l'élaboration de politiques nationales et locales dans le pays, capables de répondre aux besoins du système de soins de santé en matière de ressources humaines en vue de satisfaire la demande aux niveaux régional et national. Les universités, les syndicats de professionnels et les organisations non gouvernementales pourraient exploiter ces résultats afin d'élaborer des programmes de formation continue et des programmes diplômants intégrant les compétences essentielles requises pour les personnels de soins de santé.

$$
\begin{aligned}
& \text { الاحتياجات المُدْرَكَة للقوى العاملة في الرعاية الصحية في لبنان: خطوة نحو تخطيط مستنبر للموارد البشرية ولتطوير }
\end{aligned}
$$

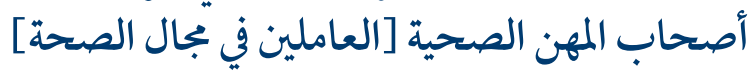

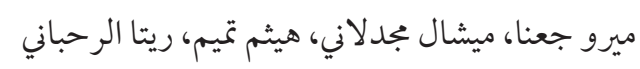

$$
\begin{aligned}
& \text { الخلاصة }
\end{aligned}
$$

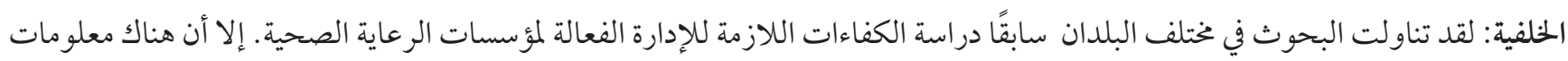

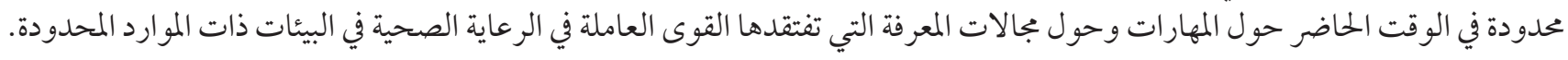

$$
\text { الهدف: كان الهدف من هذه الدراسة تقييم الاحتياجات المدركة للقوى العاملة في الرعاية الصحية في لبنان. }
$$

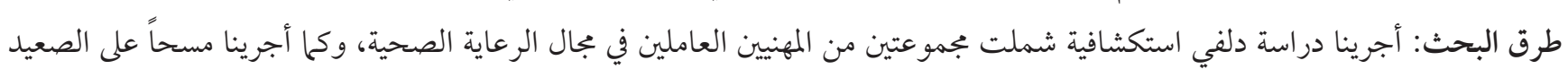

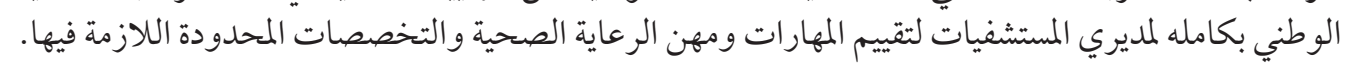

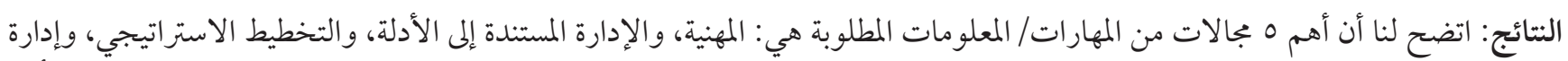

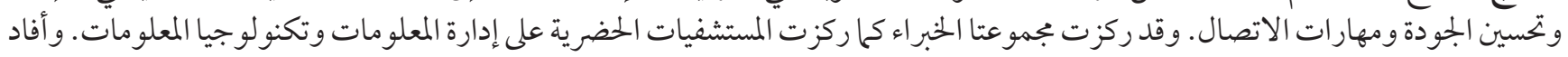

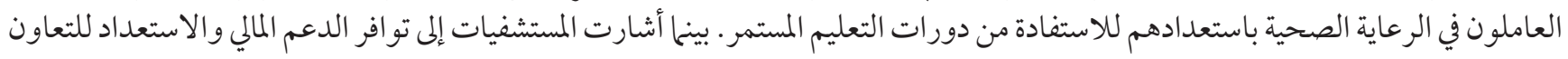

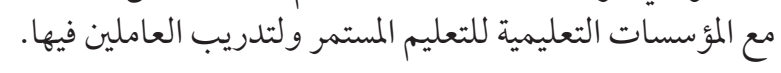

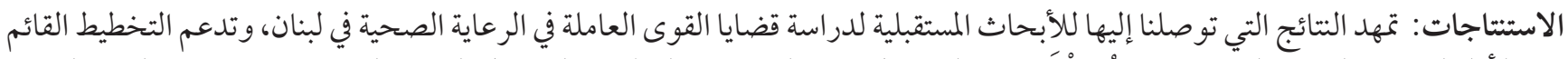

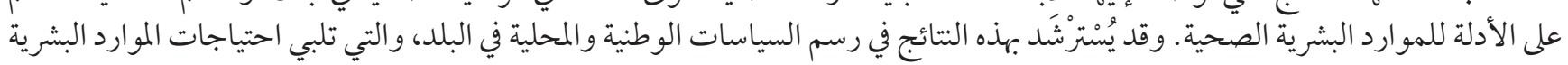

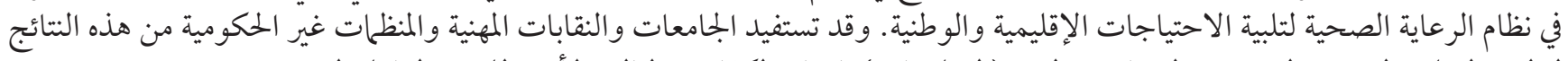

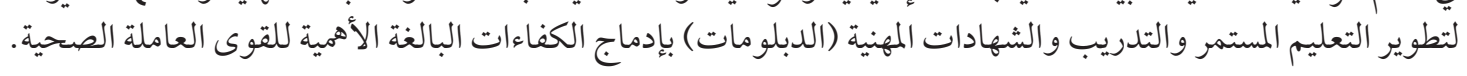

\section{References}

1. Shewchuk RM, O'Connor SJ, Fine DJ, Tyler JL. Building an understanding of the competencies needed for health administration practice. J Healthcare Manag. 2005;50(1):32-47.

2. Pruitt SD, Epping-Jordan JE. Preparing the 21st century global healthcare workforce. BMJ. 2005;330(7492):637-9. PMID:15774994

3. Stowe M, Haefner J, Behling RJ. Required knowledge, skills and abilities from healthcare clinical managers' perspectives. Acad Health Care Manag J. 2010;6(2):57-74.

4. Toygar SA, Akbulut Y. Managerial skills of hospital administrators case study of Turkey. J Health Manag. 2013;15(4):579-94. doi:10.1177/0972063413516228.

5. Chappell M, Ford K. Assessing the clinical skills training needs of community healthcare staff. J Community Nurs. 2014;28(2):69-74.

6. Spencer LM, Spencer SM. Competence at work: models for superior performance. New York: Wiley; 1993.

7. Lucia AD, Lepsinger R. The art and science of competency models: pinpointing critical success factors in organizations. Acad Manag Learn Educ. 2003;2(2):210-2.

8. Gruppen LD, Mangrulkar RS, Kolars JC. The promise of competency-based education in the health professions for improving global health. Hum Resour Health. 2012;10(1):1. doi:10.1186/1478-4491-10-43. PMID:23157696 
9. Pillay R. The skills gap in hospital management: a comparative analysis of hospital managers in the public and private sectors in South Africa. Health Serv Manage Res. 2010;23(1):30-6. PMID:20150608.

10. Calhoun JG, Vincent ET, Baker GR, Butler PW, Sinioris ME, Chen SL. Competency identification and modeling in healthcare leadership. J Health Adm Educ. 2004;21(4):419-40. PMID:15495738

11. Pruitt S, Epping-Jordan J. Preparing a global healthcare workforce for the challenge of chronic conditions. Diabetes Voice. 2008;53:38-41.

12. Chami M, Mikhael M. The saga of the Lebanese healthcare sector: reforms on the run amid persistent challenges. Beirut: Blominvest Bank; 2016 (http://blog.blominvestbank.com/wp-content/uploads/2015/05/The-Saga-of-the-Lebanese-Healthcare-SectorReforms-on-the-Run-amid-Persistent-Challenges.pdf, accessed 28 January 2018).

13. Institute of Health Management and Social Protection. National health statistics report in Lebanon. Beirut: Saint-Joseph University; 2012.

14. Ammar W. Health beyond politics. Beirut: Lebanese American University; 2009.

15. Public health. Beirut: Council for Development and Reconstruction; 2011:49-55 http://www.cdr.gov.lb/eng/progress_reports/ pr102011/Epub.pdf, accessed 28 January 2018).

16. Health indicators. Beirut: Ministry of Public Health; 2016 (https://www.moph.gov.lb/en/Pages/8/138/health-indicators, accessed 13 February 2018).

17. Sfeir R. Strategy for national health care reform in Lebanon. Beirut: Ministry of Public Health; 2007.

18. Kronfol N, Khalife J, Romanos J, Makouk J, Noun P, Ammar W. Observations on the Ministry of Public Health program of support to the hospitalization of patients in Lebanon. J Med Liban. 2014;62(1):33-9. PMID:24684124

19. DeJong J, Meyerson-Knox S. Lebanon: an overview. Montreal: Institute for the Study of International Development; 2011 (UNFPA Policy Briefs PB-2011-02; https://www.mcgill.ca/isid/files/isid/pb_2011_02_dejong.pdf, accessed 31 January 2018).

20. El-Jardali F, Alameddine M, Jamal D, Dimassi H, Dumit NY, McEwen MK, et al. A national study on nurses' retention in healthcare facilities in underserved areas in Lebanon. Hum Resour Health. 2013;11(1):11-49. PMID:24079458

21. El-Jardali F, Makhoul J, Jamal D, Ranson MK, Kronfol NM, Tchaghchagian V. Eliciting policymakers' and stakeholders' opinions to help shape health system research priorities in the Middle East and North Africa region. Health Policy Plan. 2010;25(1):15-27. PMID:19948770

22. Salameh PR, Barbour B. Continuing education of nurses in Lebanon: Evaluation and unmet needs. J Adult Contin Educ. 2006;12(2):182-94.

23. Alameddine M, Saleh S, El-Jardali F, Dimassi H, Mourad Y. The retention of health human resources in primary healthcare centers in Lebanon: a national survey. BMC Health Serv Res. 2012;12(1):419. PMID:23173905

24. Delbecq AL, Van de Ven AH, Gustafson DH. Group techniques for program planning: a guide to nominal group and Delphi processes. Glenview, Illinois: Scott Foresman; 1975.

25. Jaana M, Tamim H, Paré G, Teitelbaum M. Key IT management issues in hospitals: results of a Delphi study in Canada. Int J Med Inf. 2011;80(12):828-40. PMID:22014811.

26. Allegrante JP, Moon RW, Auld ME, Gebbie KM. Continuing-education needs of the currently employed public health education workforce. Am J Public Health. 2001;91(8):1230-4. PMID:11499109.

27. Preparing a health care workforce for the 21st century: the challenge of chronic conditions. Geneva: World Health Organization; 2005. (http://www.who.int/chp/knowledge/publications/workforce_report.pdf, accessed 31 January 2018). 